\title{
PRIMEIRAS CONCLUSÕES SOBRE O PODER DO JUIZ NA RECUPERAÇÃO JUDICIAL FRENTE ÀS DECISÕES DA ASSEMBLEIA GERAL DOS CREDORES
}

\author{
Danielle Yurie Moura, João Paulo Angelo Vasconcelos, Ana Augusta Rodrigues Westin \\ Universidade do Oeste Paulista - UNOESTE. Curso de Direito, Presidente Prudente - SP.
}

\section{RESUMO}

O presente artigo tem por objetivo refletir sobre o instituto da recuperação judicial de empresa, introduzido no ordenamento jurídico por força da Lei 11.101/2005. Com base na nova ordem legal, reflete-se sobre os sujeitos que atuam na recuperação judicial, dando-se destacada atenção ao papel deliberativo do magistrado. Demonstra-se a possibilidade de ocorrência de colisão do poder decisional do juiz com o poder deliberativo dos credores, bem como a necessidade de ambos recorrerem não somente à lei que regula a recuperação, mas também às normas contidas na Constituição Federal, sem descuidar dos princípios econômicos e não econômicos. A sobreposição da atuação judicial ante as decisões da Assembleia Geral dos Credores deve pautarse na tutela de interesses sociais, difusos e coletivos, bem como, razoavelmente, do direito dos credores.

Palavras chave: Direito Empresarial - Recuperação Judicial - Evolução Histórica - Poder do Juiz Poder dos Credores.

\section{FIRST CONCLUSIONS ON THE POWER OF JUDGE IN RECOVERY JUDICIAL DECISIONS TO THE FRONT OF THE GENERAL MEETING OF CREDITORS}

\begin{abstract}
This article aims to demonstrate how is the performance status of the bankruptcy law with the advent of the new Law 11.101 / 2005. Aimed to assess the viability of the company, highlighting the way in which it is performed and what the guys who work in bankruptcy, with main focus on the person of the magistrate and creditors. This study also looked into the collision demonstrate the power of the judge with the power of creditors, that conflict must be mindful not only the Law with respect to recovery, but also the norms contained in the Federal Constitution and the principles governing the economics and business law. We sought, therefore, point the scope of the judiciary in relation to the decisions of the General Meeting of Creditors, highlighting the principle of preservation of social, diffuse and collective interests, not forgetting, however, that the Lender also has a right to be ward.

Keywords: Business Law - Reorganization - Historical Evolution - Power of the Judge - Power of Creditors.
\end{abstract}




\section{INTRODUÇÃO}

Historicamente, o direito falimentar foi utilizado como mero meio de cobrança do devedor. À empresa em crise restava a exclusão do mercado, posto considerada nociva à economia independentemente da causa atribuída às suas dificuldades de ordem patrimonial, financeira ou econômica, ou seja, se por má administração, por inviabilidade do negócio ou em decorrência de medidas macroeconômicas previstas em políticas governamentais. Na aplicação das normas falimentares não se perquirira acerca da relevância da continuidade da empresa. No segundo pósguerra, com o incremento da atividade industrial, a globalização econômica e o aumento populacional, e seus efeitos negativos - desemprego, fome e miséria - em escala mundial -, o Brasil, diferentemente de outros países, necessitava de uma disciplina jurídica que considerasse a continuidade da empresa em crise e não o seu desaparecimento. Até 2005, vigorou o Decreto-lei $7.661 / 445$.

Alguns autores, antes mesmo do advento da Nova Lei de Falências, defendia a falência com a continuidade do negócio, o que influenciou a jurisprudência. Nesse sentido, Nelson Abrão (1975).

De seu turno, a lei atual trata a crise com um olhar diferente, conforme SIMEÃO FILHO (2009, p.32):

A crise da empresa não é jurídica, mas econômica, e como tal deve ser tratada, de forma que se possam investigar as suas causas próximas e remotas e adicionar juridicamente o lenitivo correto para superar a situação vivenciada, sempre tendo como norte a proteção da unidade produtiva ou da fonte produtora, como preconiza o artigo 47 do diploma em estudo ao mencionar que a recuperação judicial tem por objetivo a superação da situação de crise econômica- financeira do devedor, a fim de permitir a manutenção da fonte produtora, do emprego dos trabalhadores e dos interesses dos credores, promovendo, assim a preservação da empresa, sua função social e o estímulo à atividade econômica.

Vemos, portanto, que a recuperação de empresa não trata, na essência, de questões jurídicas - estas subsistem enquanto regramento de um processo ou rito, um instrumento de funcionamento da recuperação. O instituto - recuperação - está inspirado na análise econômica e leva em conta o principio da função social da empresa e o postulado da autonomia dos credores.

Mas, para que essa recuperação seja possível, é necessário que os credores, os sujeitos mais afetados diretamente nesse processo, aceitem o plano de recuperação, na forma decidida pela Assembleia Geral, órgão do processo de recuperação e de falência que tem função deliberativa, ou seja, o poder de decidir soberanamente no que diz respeito à matéria. 
Na disciplina jurídica falimentar pré-2005, o ordenamento brasileiro adotava um sistema no qual o Estado assumia a direção e controle dos desígnios da empresa em crise. O juiz exercia função administrativa, conquanto sem competência técnica para gestão. Conforme dispunha o artigo 146 da lei de 1945, detinha o poder de conceder ou negar a concordata (mera moratória), independentemente da aceitação dos credores. Nesse sentido ALVARES:

O que fica evidente é que a lei brasileira adota o sistema de que a matéria falimentar já não mais é confiada à orientação dos credores. Por ser matéria de ordem pública, por interessar ao crédito público, que precisa ser defendido, o Estado assume a completa direção, quer na parte jurisdicional, que sempre foi o caso, quer na parte administrativa. [...] (1968, p. 434)

Com o advento da nova lei, e tendo em vista o disposto no caput do seu artigo 58, ao Judiciário não cabe mais deliberar sobre a viabilidade do plano com base em critérios de conveniência e oportunidade do negócio; descabe-lhe manter aberta ou fechar a empresa. Ao Estado-juiz cumpre o controle de legalidade (sentido amplo) do processo, do procedimento.

Tal a lição de Francisco Satiro de Souza Junior e Antônio Sérgio de Morais Pitombo:

Não cabe ao juiz, portanto nenhuma margem de discricionariedade a respeito da matéria ou, em palavras mais precisas, não há na lei, quanto a esse aspecto, conceitos abertos (chamados conceitos indeterminados) que confiram ao juiz margem ampla de interpretação para a emissão dos respectivos juízos de legalidade. Assim, uma vez preenchidos os requisitos da Lei, que nesse aspecto não adota nenhuma cláusula aberta ou conceito indeterminado, e aprovado o plano pelos credores, cumpre ao juiz conceder a recuperação; se, por outro lado, não se configurar tal hipótese, cabe ao juiz decretar a falência. (2005, p. 284)

Vemos portando que ao realizar um breve estudo pelo direito falimentar, percebe-se que a lei brasileira se afasta das diretrizes geralmente reconhecidas como válidas. Ao limitar o poder do juiz, revelando uma preocupação, adotou determinado número de votos e somente se preocupou em acrescentar as exigências da classe que rejeitou o plano.

Contudo, conforme SIMEÃO FILHO (2009), quando o plano não obtém a aprovação de todas as classes, a lei concede ao juiz o poder de conceder mesmo assim a recuperação desde que o plano não implique em tratamento diferenciado entre os credores da classe que rejeitou o plano e ainda tem que na mesma assembleia tenha se obtido de forma cumulativa o voto favorável de credores que representem mais da metade do valor de créditos presentes na AGC, independente da classe, tem que ter tido a aprovação de 2 das classes de credores, se houver somente 2 classes, a aprovação de uma delas e na classe que houver sido rejeitada, ter votos favoráveis a o plano de mais de $1 / 3$ dos credores. 
Percebe-se porem que o juiz só poderá superar a rejeição, se todos os requisitos forem cumpridos cumulativamente e na mesma AGC, com isso vemos que a lei brasileira permitiu que o juiz pudesse decidir, contudo limitou seus poderes, afastando das diretrizes estabelecidas leis anteriores e até mesmo outras legislações onde predominam conceitos abertos e princípios que facilitam a intervenção do juiz para superar a decisão dos votos da AGC.

No tocante aos limites de poderes do Juiz para fins de aplicação do cram down pelo sistema brasileiro, na mesma linha adotada anteriormente Eduardo S. Munhoz entende que a interpretação sistemática do $\S 1^{\circ}$ do artigo 58 em consonância com a própria lei, o juiz não poderá deixar de conceder a recuperação, superando o veto apresentado por uma das classes de credores, quando presentes os requisitos previstos no incisos I a III do §1ㅇe e no §2을 do artigo 58." (2009,p. 55 e 56)

Portando entende-se que a palavra "poderá", descrita no artigo não está relacionada se o juiz, por sua escolha pode ou não conceder a recuperação, mas sim é um poder-dever, pois se estiverem presentes todos os requisitos previstos na lei, o juiz deverá conceder a recuperação, pois partindo das primícias de que os credores são aqueles que saberiam melhor se o plano é viável aos seus interesses, essa primícias também poderiam ser ultrajadas por razões, tais como a abstenção gerada pela falta de interesses dos credores, ausência de condições dos credores de elaborarem um plano alternativo, entre outras.

Dessa maneira deverá o juiz conceder a recuperação, pois percebe-se um interesse maior a ser preservado.

Cientificamente, é importante, pois nos remete a oportunidade de aprofundar o conhecimento e contribuir para que a presente temática amplie espaço cada vez mais efetivo nas preocupações da comunidade acadêmica das ciências jurídicas.

\section{CONCLUSÃO}

Deve-se, portanto, entender que mesmo o novo sistema tendo uma visão de mercado, não se pode esquecer que a lei ainda tem um perfil publicista, isto é, visa antes de tudo o interesse público e sendo assim, o interesse de todos os credores, colocando em segundo plano a proteção de interesses exclusivamente patrimoniais.

A tomada de decisões deve considerar o caso concreto, a casuística de cada empresa em crise, não se imiscuindo, o julgador, do controle de constitucionalidade, sempre se pautando nos princípios constitucionais que dão norte a direito recuperacional, visando à melhor solução, assim 
considerada a que equilibre a continuidade da empresa e o interesse dos credores e não estabeleça a instabilidade e insegurança jurídicas.

Consideramos, pois, interpretação mais apropriada a que prioriza a análise econômica sem descurar dos princípios constitucionais estabelecidos para a atividade econômica, tais como os indicados, exemplificativamente, no artigo 170 da Carta.

Decisões que envolvem a permanência ou não de uma empresa enquanto agente econômico, devem ser tomadas pelo mercado, que, todavia, está regulado e pressupõe a tutela estatal, mesmo que esta se opere no terreno da recuperação judicial.

\section{REFERÊNCIAS}

ABRÃO, Nelson. A continuação do negócio na falência. 1. ed. São Paulo: Universitário de Direito, 1975.

ABRÃO, Nelson. Curso de Direito Falimentar. 3. ed. São Paulo: Revista dos Tribunais,1989.

ALMEIDA, Amador Paes de. Curso de falência e concordata 20. ed. rev. e atual. São Paulo: Saraiva, 2002.

BRANCO, Gerson Luiz. Carlos. O poder dos credores e o poder do juiz na falência e recuperação judicial. Revista dos Tribunais, v. 936, p. 43. Out., 2013 Disponível em:

<http://www.revistadostribunais.com.br/maf/app/latestupdates/document?\&src=r\&srguid=i0ad8 $1816000001455078 \mathrm{~b} 2 \mathrm{e} 014412281$ \&docguid=Iccf183401aa611e3a030010000000000\& $\mathrm{hitguid}=$ Iccf 183401aa611e3a030010000000000\&spos $=47 \&$ epos $=47 \& \mathrm{td}=123 \&$ context $=73 \&$ startChunk $=1 \&$ end Chunk=1>Acesso em: 04 fev. 2014.

COELHO, Fabio Ulhoa. Comentários `a nova lei das falências e de recuperação de empresas.: (Lei no 11.101, de 9-2-2005). 2. ed. rev. São Paulo: Saraiva, 2005.

DANTAS, Renata Marques Lima. Princípio da preservação da função social da empresa no contexto da lei de falências e recuperação de empresas. Revista dos Tribunais Nordeste, v.2, p.71, Nov., 2013. Disponível em: $<$ http://www.revistadostribunais.com.br/maf/app/latestupdates/document? \&src=rl\&srguid=i0ad 81816000001455078b2e014412281\&docguid =I5f30fa4087e611e38481010000000000\&hitguid=I5 $\underline{\mathrm{f} 30 \mathrm{fa} 4087 \mathrm{e} 611 \mathrm{e} 38481010000000000 \& s p o s=57 \& e p o s=57 \& \mathrm{td}=123 \& \text { context }=129 \& \text { startChunk }=1 \& \mathrm{e}}$ ndChunk=1> Acesso em: 04 fev. 2014.

FERREIRA, Marcus Vinícius Vita. A competência universal do juízo da recuperação judicial e o princípio da preservação da empresa. Revista de Direito Bancário e do Mercado de Capitais, v. 46, p. 347, Out., $2009 . \quad$ Disponível em:<http://www.revistadostribunais.com.br/maf/app/latestupdates/document?\&src=rl\&srguid=i Oad81816000001455078b2e014412281\&docguid=le07ac500008811e1968d00008558bdfc\&hitgui $\mathrm{d}=l e 07 \mathrm{ac} 500008811 \mathrm{e} 1968 \mathrm{~d} 00008558 \mathrm{bdfc} \&$ spos $=51 \&$ epos $=51 \& \mathrm{td}=123 \&$ context=92\&startChunk $=$ 1\&endChunk=1> Acesso em: 04 fev. 2014. 
FLORIANO NETO, Alex. Atuação do juiz na recuperação judicial. Belo Horizonte: Arraes Editores, 2012.

MUNHOZ, Eduardo Secchi. Anotações sobre os limites do poder jurisdicional na apreciação do plano de recuperação judicial. Revista de Direito Bancário e do Mercado de Capitais, v. 36, p. 184, Abr., 2007.

Disponível

em:<http://www.revistadostribunais.com.br/maf/app/latestupdates/document?\&src=rl\&srguid=i Oad81816000001455078b2e014412281\&docguid=le32720d02d5411e0baf30000855dd350\&hitgui $\mathrm{d}=l e 32720 \mathrm{~d} 02 \mathrm{~d} 5411 \mathrm{e} 0$ baf30000855dd350\&spos $=52 \&$ epos $=52 \& \mathrm{td}=123 \&$ context $=116 \&$ startChunk =1\&endChunk=1> Acesso em: 04 fev. 2014.

QUEIROZ. Jorge. Quebra-cabeças. Lei de falências é boa, mas solução é econômicaadministrativa. Disponível em: <http://www.conjur.com.br/2006-fev14/lei falencias boa solucao economico-administrativa>. Acesso em: 25 jan. 2013.

REQUIÃO, Rubens. Curso de Direito Falimentar. v.1, 12. ed. São Paulo: Saraiva, 1988.

REQUIÃO, Rubens. Curso de Direito Falimentar, v.2, 12. ed. São Paulo: Saraiva, 1990.

SANT'ANNA, Rubens. Falências e Concordatas. 5. ed. Rio de Janeiro: Aide, 1985.

SIMÃO FILHO, Adalberto. Interesses transindividuais dos credores nas assembleias-gerais e sistemas de aprovação do plano de recuperação judicial.

SOARES, Sonia A. R. Os dez anos, dez meses e alguns dias da Lei 11.101/2005. In: DE LUCCA, Newton; DOMINGUES, Alessandra de Azevedo. (Coord.). Direito recuperacional: aspectos teóricos e práticos. São Paulo: Quartier Latin, 2009, p. 31-64.

SOARES, Sonia A. R. Os dez anos, dez meses e alguns dias da Lei 11.101/2005. Revista de Direito de Trabalho, v. 145, p. 213. Jan., 2012. Disponível em: <http://www.revistadostribunais.com.br/maf/app/resultList/document?\&src=rl\&srguid=i0ad8181 $6000001455078 b 2 e 014412281 \&$ docguid $=\mid 4918 a 6 e 0789811 \mathrm{e} 1940400008517971$ a \& hitguid $=\mid 4918$ a6e0789811e1940400008517971a\&spos $=25 \&$ epos $=25 \& \mathrm{td}=123 \&$ context $=6 \&$ startChunk=1\&endCh unk=1.> Acesso em: 04 fev. 2014.

SOUZA JUNIOR, Francisco Satiro de; PITOMBO Antônio Sérgio A. de Moraes (Coord.). Comentários à Lei de recuperação e falência: Lei 11.101/2005 São Paulo: Editora Revista dos Tribunais, 2005. Vários Colaboradores.

TOLEDO, Paulo F. C. Salles de; ABRÃO, Carlos Henrique. Comentários à lei de recuperação de empresas e falência. 5. ed. rev. , atual. e ampl. São Paulo : Saraiva, 2012.

TOLEDO, Paulo Fernando Campos Salles. O plano de recuperação e controle judicial da legalidade. Revista de Direito Bancário e do Mercado de Capitais v. 60, p. 307. Abr., 2013 Disponível em:

<http://www.revistadostribunais.com.br/maf/app/latestupdates/document?\&src=rl\&srguid=i0ad $86000001455078 \mathrm{~b} 2 \mathrm{e} 014412281$ \&docguid=la7503300e53311e295ec010000000000\&hitguid=la75 03300e53311e295ec010000000000\&spos=40\&epos $=40 \& \mathrm{td}=123 \&$ context $=28 \&$ startChunk $=1 \&$ end Chunk=1. Acesso em: 04 fev. 2014. 
VALVERDE, Trajano de Miranda. Comentários à lei de falências: (Decreto-Lei no 7.661, de 21 de Junho de 1945). 4. ed. rev. e atualizada Rio de Janeiro: Revista Forense, 1999. 